\title{
EFFECTIVENESS OF VARIABLE - PLAYING METHODOLOGY (VIM) IN BEGINNER FLORBALL PLAYERS.
}

\author{
D. Krushkov ${ }^{1}$, M. Ivanova ${ }^{2} *$ Z. Markovic ${ }^{3}$ \\ ${ }^{1}$ Department Football and Tennis, Sector Hockey, National Sports Academy “Vassil Levski” \\ Sofia, Bulgaria \\ ${ }^{2}$ Departament Phisical Education and Sport, Trakia University, Stara Zagora, Bulgaria \\ ${ }^{3}$ Faculty of Education, Jagodina University of Kragujevac, Kragujevac, Serbia
}

\begin{abstract}
Considering the different teaching methodologies, we find that Variable-Playing Methodology (VIM) is recommended as an effective tool for initial training in the various collective - team sports. The basis of the VIM is the development of technical skills and motor habits in conditions close to the game. Learning and refining individual technical and tactical techniques in variations or through the game itself is a basic principle of VIM, advocated and successfully applied in many collective sports basketball, volleyball, football, handball, hockey, and more. The introduction of VIM in the training of adolescent football players will be important from a scientific and purely applied point of view, as a sport on a global scale is still in its 'young' age, and is barely passing in Bulgaria.

The purpose of the present study is to apply VIM efficacy in the training of 8-9 year-old children in floorball training to trace and analyze the development of the main technical and conditioning training indicators.

The contingent of experimental work and sports-pedagogical testing were 16 children born in 2009 practicing floorball in Bulgaria - a control group and 16 children of the same age practicing playing at the Skala Club, Melitopol, Ukraine - an experimental group.
\end{abstract}

Key words: floorball, technical indicators, physical or conditional indicators

\section{INTRODUCTION}

The floorball (in English "floor" and "ball") is a group sports game derivative of hockey practiced indoors on a hard, plain floor with a stick and plastic hollow ball. All technical and tactic actions such as leading, passing, taking over control, shooting, eliminations, etc. are being fulfilled in specific conditions via a sports device - stick; close in his form to the hockey stick (1). The training is a multi-factor process where all of the sides - the technical, physical, psychological, and theoretical ones have a great influence on the individual players' development (2-4). In our investigations regarding the innovative approaches and methodology regarding the

\footnotetext{
*Correspondence to: Maria Ivanova, Departament Phisical Education and Sport, Trakia University, Stara Zagora, Bulgaria, Email: mimi0106@abv.bg, Mobile:+359887527829
}

initial training of the children in the group sports we found out that the variable playing methodology (VPM) is highly recommendable as an effective instrument for the training in the initial stages/levels of the sports preparation. From the methodological point of view, the problem here with the variableplaying methodology is well defined and implemented in the different group sports, but in the floorball area we consider the issue as a non-concerned enough. We could not find data regarding the influence of such practices on the training effectivity upon the young floorballers in the available literature, but we found a lot of information regarding similar investigations in the hockey and floorball (5). According to Antonov (6) and Wain (7) in the core of the variable-playing methodology is the formation of moving ability under conditions pretty close to the real playing ones. Antonov defines the primary importance of the preciseness of the 
technical aspect in the training of the young hockey players (10-12 years old), as well as the fact that the speed of the technical actions is an important factor in the whole formation of rational and effective velocity technique in the future. According to the same author, the process of the technical training and development could be found in the preciseness and fast application of the technique approaches, and it should be done according to a methodology where the playing assets of realization in real-time (playing method) are being prioritized. The study and development of the separate technical-tactic skills under variable conditions or via the game itself is the main principle of VPM. (8). The implementation of VPM in the young player's training will have an important impact from the scientific and purely applicable point of view as this sport is still in its "teenage" globally, and in Bulgaria it is more similar to a child who still cannot walk. Taking into consideration the condition that via VPM the technical skills will be studied and implemented via optimal-speed motion, and the development of the technique and the different qualities will be done in a unique and non-separable process (like an entity), the effect tracing of the application of this methodology will give us an important additional piece of information regarding the effectiveness of the initial floorball training.

\section{METHODS}

The scope of our investigation is to establish, trace and analyze the development of the main aspects of the physical and technical preparation via the development and implementation of the specialized VPM in the training testing environment for 8-9-year-old children, systematically playing floorball, and to compare the efficiency of the VPM methodology with the traditional training applied regarding the sports activity of such players.

This scope regards the resolution of the following tasks:

1. Investigation and analysis of the accessible sources of literature (both paper and electronic ones).

2. Development and implementation of VPM in the training of 8-9-year old players according to variable models, established in hockey.

3. Establishment of the effect of VPM's usage via the definition of the percentage rate of increase of the investigated parameters of physical and technical preparation. Establishment of the effect of VPM's usage via the definition of the percentage rate of increase of the investigated parameters of physical and technical preparation. The target group of the experimental work and sports-technical testing have been 16 children born in 2009, playing floorball in Bulgaria; they set up the experimental group (EG). For a better understanding of the process and better scoping, we made up also a control group (CG) from 16 children the same age, practicing floorball playing in the "Scala" (Rock) club, Melitopol town, Ukraine. At the beginning of the experiment in January 2018 the overall quantity of the individuals, participating in the process and testing was 32 (16 from the CG and 16 from the EG) but at the end of the investigation in October 2018, the balance had changed.

In Table 1 the overall quantity of the individuals is shown - CG and EG who participated in the experimental, investigational, and technical-study work.

Table 1. Target group of the investigation of eg and $c g$

\begin{tabular}{|l|c|c|}
\hline Group & April 2018 & October 2018 \\
\hline EG (SCF NSA/Levski) & 16 & 16 \\
\hline CG (FLC Scala) & 16 & 16 \\
\hline Total & 32 & 32 \\
\hline
\end{tabular}

The object of the investigation is the two patterns of sports floorball preparation - the traditionally used in Ukraine methodology and VPM investigated and implemented by us.

The subject of the investigation is the influence and effectivity of VPM on the development - the growth and dependence of the main parameters of the physical and technical preparation. Regarding the fulfillment of the scope and the resolution of the tasks involved the following scientifical methods have been used: 
1. Search, analysis, and review of the information regarding traditional and electronic sources of information;

2. Sports-pedagogy experiment;

3. Sports-pedagogy testing;

4. Mathematical-statistics methods:

- Variation analysis - finding of the averages and coefficients for scattering and variation of indicators;

- calculation of the relative growth, personally of each participant according to the formula $\Delta=(\alpha \neg 1-\alpha \neg 2) \div \alpha \neg 1 \times 100$ and the average statistical growth of the group as a whole by formula $\sum$ average $=\sum \Delta / \mathrm{n}$. The

pedagogical experiment has been made during one sports-participational year in the period from 10 January 2018 until 10 October 2018 with players born in 2009.

In the experimental group, there were 16 boys from the sports clubs "NSA" and "Levski" trained in one group. At the beginning of the pedagogical experiment organized the 16 participants have had a 1-year experience of training. In the control group 16 boys from the sports clubs "Scala" (Melitopol town in Ukraine) took a hand; they had 2-2,5 years of experience in the training (Table 1).
For the investigation process we have worked around the methodology for early floorball training for 9-year old children using as a basis the principles and methods of the variableplaying methodology in hockey, proposed by Antonov A. 2006 and Wain H., 2000.

During the experiment process as obligatory requirements of the methodology, the following principles have been established:

$\varnothing$ The training-study activities are being gone through in small groups of 12 to 16 players who have minimal training experience of 1 year at the beginning of the training;

$\varnothing$ Variational and playing methods with elements of group separation of 4 to 6 players have been prioritized during the educational process.

The experimental method includes a system of 90 training activities with a prolongation of 60 minutes. The overall employment in the training-study process consists of 90 astronomical hours. The proportion of the means applied according to their classification is shown in Table 2.

Table 2. Percentage correlation between the means

\begin{tabular}{|l|c|c|}
\hline Means & Percentage & Hours \\
\hline General development exercises (GDE) & $15 \%$ & 14 \\
\hline Special preparatory exercises (SPE) & $15 \%$ & 14 \\
\hline $\begin{array}{l}\text { Competitive exercises (SE) } \\
\quad \text { variable exercises 67\%/40 h } \\
\text { - stereotypical exercises 33\%/22 h }\end{array}$ & $70 \%$ & 62 \\
\hline Total & $100 \%$ & 90 \\
\hline
\end{tabular}

According to the established schedule of the field with artificial grass in NSA "Vasil Levski" in April 2018 the initial testing is carried out, and at the beginning of October 2018 the final testing was carried out. The competitors from EG and CG covered the control tests reflected in the Table 3 and 4 regarding control and assessment of physical training (TB 1) and of technical training (TB 2).

Table 3. Tb 1 sports pedagogical tests for control of physical preparation

\begin{tabular}{|l|l|c|c|}
\hline № & \multicolumn{1}{|c|}{ Name of the test } & Unit & Accuracy \\
\hline 1 & Sprint running - 10 m - SpR10 & $\mathrm{Sec}$ & 0,01 \\
\hline 2 & Sprint running - 30 m - SpR30 & $\mathrm{Sec}$ & 0,01 \\
\hline 3 & Shuttle run - 3x10 (ShR 3x10) & $\mathrm{Sec}$ & 0,01 \\
\hline 4 & Dynamometry of the right hand DRH & $\mathrm{Kg}$ & 1 \\
\hline 5 & Dynamometry of the left hand DLH & $\mathrm{Kg}$ & 1 \\
\hline 6 & Long jump from a place - LJP & $\mathrm{Cm}$ & 1 \\
\hline 7 & $\begin{array}{l}\text { High jump - HJ } \\
\text { High jump - ST }\end{array}$ & $\mathrm{Cm}$ & 1 \\
\hline
\end{tabular}


Table 4. Tb 2 of tests for control and evaluation of technical preparation

\begin{tabular}{|l|l|c|c|}
\hline № & Name of the test & Unit & Accuracy \\
\hline 1 & Sprint guide - 20 m (SG 20) & Sec & 0,01 \\
\hline 2 & Sprint guide - slalom - SGS & Sec & 0,01 \\
\hline 3 & Short distance feed - 6 m (SDF6) & score & 1 \\
\hline 4 & Shooting push through the air - 6 m. (SPA6) & score & 1 \\
\hline 5 & One-touch shooting - 6 m. (OTS6) & score & 1 \\
\hline
\end{tabular}

\section{Research methods}

The data obtained as a result of the sportspedagogical experiment are subjected to mathematical and statistical analysis by means of the specialized program IMB SPSS Statistics (Gigova V., Shandurkova S., 2014):

Variation analysis (VA) - to establish the average level, the dispersion and the variability of the indicators;

\section{RESULTS}

In Tables 5-8 we have reflected the average values and the coefficients of scattering and variation of the studied indicators of physical preparation and technical preparation of the athletes from $\mathrm{CG}$ and $\mathrm{EG}$.

Table 5. Variation indicators of physical preparation from the first testing

\begin{tabular}{|c|c|c|c|c|c|c|c|c|c|c|}
\hline \multirow{2}{*}{ № } & \multirow{2}{*}{ Indicator } & \multirow{2}{*}{ Unit } & \multicolumn{6}{|c|}{ CG } & \multicolumn{1}{|c|}{ EG } \\
\cline { 4 - 10 } & & & $\boldsymbol{X}$ & $\mathbf{V}$ & $\mathbf{A s}$ & $\mathbf{E x}$ & $\boldsymbol{X}$ & $\mathbf{V}$ & $\mathbf{A s}$ & $\mathbf{E x}$ \\
\hline 1 & SpR10 & $\mathrm{Sec}$ & 2,90 & 6,51 & 0,071 & 0,75 & 2,78 & 7,74 & $-0,411$ & $-1,229$ \\
\hline 2 & SpR30 & $\mathrm{Sec}$ & 6,58 & 8,38 & $-0,654$ & $-0,475$ & 6,45 & 7,16 & 0,158 & $-1,409$ \\
\hline 3 & ShR $3 \times 10$ & $\mathrm{Sec}$ & 8,52 & 7,12 & $-0,079$ & $-0,547$ & 8,91 & 4,12 & 0,079 & $-1,339$ \\
\hline 4 & $\mathrm{DRH}$ & $\mathrm{Kg}$ & 16,64 & 5,59 & $-0,084$ & $-1,003$ & 16,89 & 5,89 & $-0,112$ & $-0,996$ \\
\hline 5 & $\mathrm{DLH}$ & $\mathrm{Kg}$ & 16,44 & 6,32 & 0,123 & $-0,791$ & 16,32 & 6,86 & 0,120 & $-1,167$ \\
\hline 6 & $\mathrm{LJP}$ & $\mathrm{Cm}$ & 137,92 & 8,12 & 0,676 & $-0,911$ & 137,14 & 6,99 & 0,192 & $-1,519$ \\
\hline 7 & $\mathrm{HJ}$ & $\mathrm{Cm}$ & 24,21 & 11,81 & 0,186 & $-1,208$ & 23,5 & 17,49 & 0,217 & $-1,177$ \\
\hline
\end{tabular}

Table 6. Variation indicators of physical preparation from the second testing

\begin{tabular}{|c|c|c|c|c|c|c|c|c|c|c|}
\hline \multirow{2}{*}{ № } & \multirow{2}{*}{ Indicator } & \multirow{2}{*}{ Unit } & \multicolumn{6}{|c|}{ CG } & \multicolumn{4}{|c|}{ EG } \\
\cline { 4 - 11 } & & & $\boldsymbol{X}$ & $\mathbf{V}$ & $\mathbf{A s}$ & $\mathbf{E x}$ & $\boldsymbol{X}$ & $\mathbf{V}$ & $\mathbf{A s}$ & $\mathbf{E x}$ \\
\hline 1 & SpR10 & $\mathrm{Sec}$ & 2,88 & 6,35 & $-0,041$ & 1,045 & 2,73 & 7,65 & $-0,370$ & $-1,323$ \\
\hline 2 & SpR30 & $\mathrm{Sec}$ & 6,49 & 8,16 & $-0,981$ & $-0,205$ & 6,35 & 7,52 & 0,007 & $-1,253$ \\
\hline 3 & ShR $3 \times 10$ & $\mathrm{Sec}$ & 8,39 & 7,03 & $-0,099$ & $-0,582$ & 8,81 & 4,05 & 0,030 & $-1,494$ \\
\hline 4 & $\mathrm{DRH}$ & $\mathrm{Kg}$ & 16,80 & 4,99 & 0,117 & $-0,667$ & 17,15 & 5,98 & $-0,001$ & $-0,931$ \\
\hline 5 & $\mathrm{DLH}$ & $\mathrm{Kg}$ & 16,60 & 6,38 & 0,91 & $-0,623$ & 16,50 & 7,11 & 0,150 & $-1,174$ \\
\hline 6 & $\mathrm{LJP}$ & $\mathrm{Cm}$ & 139,57 & 8,26 & 0,838 & $-0,743$ & 138,92 & 6,86 & 0,443 & $-1,269$ \\
\hline 7 & $\mathrm{HJ}$ & $\mathrm{Cm}$ & 25,00 & 10,96 & 1,431 & 2,340 & 25,78 & 10,74 & 0,534 & $-0,928$ \\
\hline
\end{tabular}

Table 7. Variation indicators of technical preparation from the first investigation

\begin{tabular}{|l|l|c|c|c|c|c|c|c|c|c|}
\hline \multirow{2}{*}{ № } & \multirow{2}{*}{ Indicator } & \multirow{2}{*}{ Unit } & \multicolumn{6}{|c|}{ CG } & \multicolumn{4}{|c|}{ EG } \\
\cline { 4 - 10 } & & & $\boldsymbol{X}$ & $\mathbf{V}$ & $\mathbf{A s}$ & $\mathbf{E x}$ & $\boldsymbol{X}$ & $\mathbf{V}$ & $\mathbf{A s}$ & $\mathbf{E x}$ \\
\hline 1 & SG 20 & Sec & 10,00 & 8,75 & $-0,285$ & 0,099 & 13,54 & 5,44 & 0,011 & $-0,988$ \\
\hline 2 & SGS & Sec & 39,99 & 7,92 & $-1,069$ & 1,100 & 51,95 & 5,71 & $-0,414$ & $-0,751$ \\
\hline 3 & SDF6 & score & 16,71 & 12,2 & 0,821 & $-0,049$ & 10,50 & 15,73 & 0,477 & $-0,151$ \\
\hline 4 & SPA6 & score & 6,35 & 15,86 & 0,193 & $-0,819$ & 5,07 & 16,17 & 0,801 & 1,160 \\
\hline 5 & OTS6 & score & 5,21 & 15,36 & $-0,437$ & $-1,229$ & 4,42 & 14,61 & $-0,692$ & $-0,252$ \\
\hline
\end{tabular}


Table 8. Variation indicators of technical preparation from the second investigation

\begin{tabular}{|c|l|c|c|c|c|c|c|c|c|c|}
\hline \multirow{2}{*}{ № } & \multirow{2}{*}{ Indicator } & \multirow{2}{*}{ Unit } & \multicolumn{6}{|c|}{ CG } & \multicolumn{4}{|c|}{ EG } \\
\cline { 4 - 11 } & & & $\boldsymbol{X}$ & $\mathbf{V}$ & $\mathbf{A s}$ & $\mathbf{E x}$ & $\square \square$ & $\mathbf{V}$ & $\mathbf{A s}$ & $\mathbf{E x}$ \\
\hline 1 & SG 20 & Sec & 9,84 & 9,53 & $-0,652$ & 0,265 & 11,53 & 9,80 & $-0,036$ & $-0,446$ \\
\hline 2 & SGS & Sec & 38,12 & 9,02 & $-0,729$ & 0,489 & 45,24 & 5,25 & $-1,115$ & 1,070 \\
\hline 3 & SDF6 & score & 17,57 & 11,53 & 1,075 & 0,504 & 14,28 & 14,89 & 0,514 & 0,038 \\
\hline 4 & SPA6 & score & 6,85 & 11,22 & 0,264 & $-1,123$ & 6,64 & 11,22 & 0,433 & $-0,394$ \\
\hline 5 & OTS6 & score & 5,92 & 12,33 & 0,113 & $-0,856$ & 5,07 & 14,39 & $-0,113$ & $-0,856$ \\
\hline
\end{tabular}

The results of the mathematical processing of the values of the athletes from CG and EG investigated by the indicators of physical preparation and technical preparation and the established percentage growth/gain are presented in Tables 9 - 12.

Table 9. Average growth of physical preparation ( $p p$ ) indicators for the $c g$

\begin{tabular}{|l|l|l|l|l|l|l|l|}
\hline Test/PP & SpR30 & SpR10 & LJP & HJ & ShR 3x10 & DRH & DLH \\
\hline Growth,\% & & & & & & & \\
\hline
\end{tabular}

Table 10. Average growth of physical preparation ( $p p)$ indicators for the eg

\begin{tabular}{|l|l|l|l|l|l|l|l|}
\hline Test/PP & SpR30 & SpR10 & LJP & HJ & ShR 3x10 & DRH & DLH \\
\hline & & & & & & & \\
\hline Growth,\% & $\mathbf{0 , 8 2}$ & $\mathbf{1 , 4 5}$ & $\mathbf{1 , 3 2}$ & $\mathbf{1 1 , 1}$ & $\mathbf{1 , 0 1}$ & $\mathbf{1 , 5 6}$ & $\mathbf{1 , 1 3}$ \\
\hline
\end{tabular}

Table 11. Average growth of technical preparation ( $t p$ ) indicators for the cg

\begin{tabular}{|l|l|l|l|l|l|}
\hline Test/TP & SG 20 & SGS & SDF6 & SPA6 & OTS6 \\
\hline Growth, \% & & & & & \\
\hline
\end{tabular}

Table 12. Average growth of technical preparation ( $t p$ ) indicators for the eg

\begin{tabular}{|l|l|l|l|l|l|}
\hline Test/TP & SG 20 & SGS & SDF6 & SPA6 & OTS6 \\
\hline & & & & & \\
\hline Growth, \% & 15,27 & 12,77 & $\mathbf{3 6 , 5 4}$ & 12,90 & 16,19 \\
\hline
\end{tabular}

\section{DISCUSSION}

Based on the review of the average values and the variability of the studied indicators reflected in tables 5-8, the following summaries can be made:

1. The analysis of the average level of the studied physical and technical indicators shows that at the beginning of the experiment the dominant role concerning the average values was played by CG. This finding is logical, given the fact that the children included in the CG before the experiment had more training and competition experience than those in EG. At the end of the study, this trend is maintained.

2. In both groups - KG and EG we find that the dispersion at the average level in most of the indicators studied by us in both studies is within the norm, both in PP and TP. This fact gives us reason to subject the results of research to establish and objectively compare the average height between the first and second testing in CG and EG.

3. The analysis of the coefficient of variation shows that during the experimental period the players show a slight tendency of "homogenization" of the indicators of technical training, as the statement is more valid for CG. The results give us grounds to subject the test results to additional studies to track the change, dynamics, and growth of indicators and to draw conclusions about the effectiveness of the applied methodology, operating with the established relative values.

In this case, the data is processed using the formulas for calculating the relative growth of each participant personally (1) and establishing 
the average statistical growth of the group as a whole (2).

$$
\begin{aligned}
& \Delta=(\alpha 1-\alpha 2) \div \alpha 1 \times 100(1) \\
& \Delta \text { - relative growth, } \% ; \\
& \alpha 1-\text { data from October } 2017 ; \\
& \alpha 2-\text { data from March } 2018 \\
& \quad \sum \text { average }=\sum \Delta / \mathrm{n}(2)
\end{aligned}
$$

Saverage - average statistical growth in the group, \%;

$\sum \Delta-$ a sum of relative increments, $\%$;

$\mathrm{n}$ - number of participants in the group $(\mathrm{n}=16)$

- Analyzing the data from the growth of the indicators of PP and TP after the methodology applied and the conducted experiment, the obtained data is summarized and presented in Tables 9 -12, where we can interpret and draw the following conclusions for practice and science:

- the general picture of the growth of the indicators of PP in both groups is distributed in the range from 1 to $3 \%$ (Tables 9-10).

- An exception is observed only in EG for the indicator - high jump (11.1\%). Based on the obtained data, we find an increase in the indicators in both groups, but in EG we observe a larger increase in 5 out of 7 indicators, which gives us reason to assume that our experimental methodology has had a more significant impact on the development of the studied by us PP indicators. The difference in growth between CG and EG is not large, so a more detailed conclusion can be made when conducting longer studies, with a larger number of participants in the experiment, as well as subjecting the data to comparative analysis. It should also be noted that the increase in the given values may be related not to the application of the methodology, but simply to the natural development of the growing organism.

- Analyzing the summarized data on the growth of TP, reflected in Tables 11 and 12, it is clear that we observe slightly different dynamics compared to that of PP, for example, the range of growth is from 1.68 to $36.54 \%$. It should also be noted that in the EG there is a larger increase in all five indicators. This in turn can be an indicator of the effectiveness of the applied experimental VPM. This high increase in EG may be because the overall level of development of technical indicators in EG is much lower at the beginning of the experiment than that of CG.

- We should note that analyzing the data from the PP, we observe lower values of growth, etc. the phenomenon of "plateau or ceiling", which is the limit of physical capabilities in a given age group. In this regard, the growth of PP indicators is more limited.

- Analyzing the indicators of TP, we observe a larger increase, because the phenomenon of "plateau", with this preparation and age, is not so highly observed.

- The results of the research could be used to develop tests for control and evaluation of PP and TP in 9-year-old floorball players, similar to the established experience in hockey in Bulgaria (Antonov and colleagues 2001; Antonov 2006; Antonov and Dimitrieska 2013), but a greater range of experimental subjects, further probation of tests and more indepth statistics are needed.

\section{CONCLUSIONS}

Based on the study and analysis of available literature on the problem, the experiment and testing, mathematical and statistical processing and content analysis of research results give us reason to draw logical conclusions and recommendations for sports and pedagogical practice.

1. The problem we studied in the field of floorball has not been developed at all in Bulgaria, as far as Ukraine is concerned, the variant-game methodology is applied in the training of 8-10-year-olds, but in the field of research, the problem is not well studied and analyzed.

2. In the age group from 8 to 9 in the development of physical qualities it is necessary to apply an accessible variablegame method in which to emphasize the effective study of basic technical elements and techniques in motion, in a pleasant atmosphere and positive emotions.

3. We note the positive impact of dividing the general group of up to 16 people into subgroups of 4-6 people, which has a positive impact on the leadership qualities of the participants and more effective management of the training process and more interactions with the ball.

4. Examining the growth of $\mathrm{CG}$ and EG, we note that the dynamics of the development of physical qualities in EG is greater in 5 of 7 indicators, but the study period does not allow to study a given side of the study with sufficient degree to say that the applied methodology has a positive impact. Provided that the average data on physical qualities in EG are higher, it is still possible to achieve greater growth compared to CG. However, we believe that this is not enough to say that it is the methodology that has a 
positive effect, and not natural growth and development or statistical error.

5. In the study of the technical indicators of CG and EG it became clear that at all points, the growth of EG is higher. We find a tendency that the increase of the indicators characterizing the physical preparation is insignificant - from $0.82 \%$ to $11.1 \%$ in comparison with the one for the technical one from $1.68 \%$ to $36.54 \%$. This fact eloquently shows us that for a relatively short period of time - 6 months, the experimental methodology has a more dynamic impact on the development of technical training compared to the dynamics of development of the indicators characterizing the PP.

6. The tests used in the pedagogical experiment, one part developed by the Ukrainian Floorball Federation and the other by us, allow us to prepare a normative base for control and evaluation in a larger contingent of subjects, and after mathematical and statistical processing of the results of PP and TP.

7. Developed by us in the implementation of the experiment - variable-game methodology showed its effectiveness, as it positively and to a greater extent influenced the growth of key indicators that have a significant impact on the development of sports training of adolescent floorball players studying in the natural environment and atmosphere of the game.

\section{KRUSHKOV D., et al.}

\section{REFERENCES}

1. Krushkov D., Efektivnost na variativnoigrovoto obuchenie pri nachinaeshti sastezateli po florbol, MR, NSA, 2019.

2. Zhelyazkov Tsv., Dasheva, D., Osnovi na sportnata trenirovka, BOLID-INS, S., 2017.

3. Antonov A., Dimitrieska, T., Normativi za planirane, control i otcenka na sportnata podgotovka po hockey, NSA Pres, Sofia 2013.

4. Antonov A., Analysis and Detection of the Degrees and Direction of Correlations between Key Indicators of Physical Fitness of 10-12-year-old Hockey Players, Int J Bioautomation, 23(3), pp. 303-314, 2019.

5. Dimitrov, L., Sistema na sportnata podgotovka na deza i junoshi po futbol, habilitazionen trud, S. 2000.

6. Antonov, A., Efektivnost na variativno igrovoto obucenie na 10-12 godishni deza sistemno zanimavashti se s hokey, NSA, 2006.

7. Wein, H., The key to better hockey. An optimal learning and coaching model to unlock and develop the innative potential on young hockey players, RHFE, Spain 2000.

8. Antonov, A., Gŭdev, M., Dimitrov, L., Vliyanie na hokeǐniya stik vŭrkhu proyavlenieto na bŭrzinata pri 12-godishni sŭstezateli po khoker na treva,NM spisanie"Sport i Nauka",br. 6/2001, str. 42 -465 . 